\title{
Relating Open Innovation, Innovation and Management Systems Integration
}

\begin{abstract}
Purpose: The aim of this article is to analyze the impact of the level of Integration of Management Systems (IMS) over product and process Innovation Capabilities (IC), by considering the role of Open Innovation (OI) activities as a moderating effect of those relationships.
\end{abstract}

Design / Methodology / Approach: A longitudinal empirical study was performed on an existing Spanish panel database that contains information related to innovation, where 9,765 companies were selected for the panel analysis. A logit approach with random effects was considered.

Findings: The level of IMS positively influences process and product IC. Moreover, external cooperation, and using it a high extent not only positively moderate the effects of the level of IMS over process IC, but also of process over product IC, where it becomes indispensable for its effect to be positive. Finally, investing in external knowledge is a positive moderator of the effects of the level of IMS over both: process and product IC.

Originality / Value: This is one the first studies on empirically finding evidence of the impact of the level of IMS on process and product IC, and of the moderating effect of performing $\mathrm{Ol}$ activities in order to achieve higher process and product IC through the IMS.

Keywords: Level of Integration of Management Systems, Open Innovation, Process and product innovation capabilities.

\section{Introduction}

When analyzing Management Systems (MSs), it has been broadly accepted to research on ISO 9001 as a Quality MS (QMS) and ISO 14001 as an Environmental MS (EMS) because of the great number of companies that have implemented it worldwide (ISO, 2015) and its traceability. Thereby, several studies have analyzed separately how each of them interact with process and product innovations. 
On the one hand when relating ISO 9001 and innovation, existing literature has generally considered it as a part of the Total Quality Management (TQM) continuous improvement process, where empirical evidence shows that process innovations can be achieved by the adoption of more efficient MSs through organizational overhauls (Petroni et al., 2003) and can even cause radical innovations when it has been able to achieve a cultural change (Moreno-Luzon et al., 2013). Furthermore, its implementation does not always affect innovativeness, because its success is closely related to other factors including the process and strategic management and how open the organization is (Hoang et al., 2006), which can also partially explain why in other studies innovation has not been found significantly influenced by the implementation of QMSs according to managers (Antunes et al., 2009).

On the other hand, EMSs have been considered as a catalyzer for technological innovation activities (Radonjic \& Tominc, 2011), and that its implementation can also have a positive influence on environmental product innovations even if it does not necessarily implicate the increment on patents (Wagner, 2007). Moreover, the way of getting innovations is related to the level of adoption of the EMS and its structural innovations (Llach et al., 2007) so that its adoption is not only an innovation itself but it also encourages for other innovations (Carruthers \& Vanclay, 2012). Nonetheless, other studies have not been able to find a clear casualty of EMSs over process innovations (Ziegler \& Seijas Nogareda, 2009), or on product innovations (Wagner, 2008). It has also been pointed out that the collaboration between companies among a Supply Chain when adopting EMSs is an important factor in order to get larger and wider innovations (Prajogo et al., 2014) because of the importance not only of internal but also of external knowledge in this process (Gavronski et al., 2012).

The concept of Integration of Management Systems (IMS) has been defined as the joint management of function specific MSs such as QMS, EMS, Occupational health and safety, Social Responsibility, among others (Jørgensen et al., 2006) by means of a more effective and unique IMS (Beckmerhagen et al., 2003) by using common resources (Bernardo et al., 2009). Hence, integrating QMSs (e.g., TQM or ISO 9001) and EMSs (e.g., ISO 14001) is the main focus of study of this investigation due to their high acceptance among companies (ISO, 2015) and literature (e.g., Karapetrovic \& Willborn, 1998; Jørgensen et al., 2006; Bernardo et al., 2009). 
Regarding the role of IMS on innovation, empirical evidence shows that integration characteristics are positively related to innovation and customer satisfaction, being both of them referred as the benefits of IMS. In this empirical research performed in Spanish companies, results, although exploratory, suggest that the IMS help enterprises to manage their MSs as well as to incorporate innovation as part of their systems (Simon \& Petnji Yaya, 2012). From a different perspective relating IMS and innovation, the research carried out by Bernardo (2014) indicates that IMS can be classified as incremental, internal and organizational innovation, where integration aspects will determine the integration level, and that this in turn will implicate the innovation management performance which relationship is mediated by the market turbulence.

Even if the tendency of studying the relationships between the MS or IMS and innovation has been more analyzed during the last years, literature analyzing the effects of the level of IMS on the process and product innovations is anecdotic, especially when introducing open innovation $(\mathrm{Ol})$ effects. Hence, there are still no concluding results when analyzing each of the MSs separately nor of IMS, so a better understanding is required on how the level of IMS can lead to improving process and product IC by also considering the role of OI. Consequently, the aim of this study is to try to fill this gap with empirical evidence from the Spanish market, grounded on the Resource - Based View (RBV).

\section{Theoretical framework}

Innovations have been classified as process, product, organizational and marketing innovations, depending on the field in which it is developed, which can also lead to having relationships between them (OECD, 2005). Moreover, the RBV supports the concept of the transformation of resources into desirable outputs where capabilities are necessary to the creation of a competitive advantage - innovations - or superior performance (CruzCázares et al., 2013), so process and product Innovation Capabilities (IC) relationships are to be analyzed - although not how those IC are assembled - in the context of the IMS.

When relating innovation and IMS, previous researches have classified it as an organizational innovation (Jørgensen et al., 2006; Salomone, 2008; Bernardo, 2014) because, since it implicates managing systems on a single but more efficient way, it is a new organizational method in the firm business practices as defined by the OECD (2005); however, its effects on process and product innovations have been scarcely tested empirically. 
From another angle, when relating the role of IMS on innovation, empirical evidence shows that the IMS benefits are positively related to innovation and customer satisfaction, where results, although exploratory, suggest that the IMS helps enterprises to manage their MSs as well as to incorporate innovation as part of their systems (Simon \& Petnji Yaya, 2012). Additionally, the level of IMS can affect to the innovation management performance which could be evidenced by means of the benefits of the IMS, improved financial results, new processes and products and new capabilities and that moreover, this improvement would be affected by external market turbulence (Bernardo, 2014).

Furthermore, during the last years, ISO (2013) has reported to show a steady worldwide increase in certifications based on QMSs and EMSs and, since (i) the level of IMS can be measured from companies that have implemented at least two MSs, and (ii) the relationships between innovation and QMS and EMS have been mostly related from a function specific MS's standpoint, the next subsections will be based on the existing literature for analyzing and developing hypotheses regarding the relationships of the level of IMS with process and product innovations as well as the role of open innovation.

\subsection{IMS and Process IC}

When considering merely organizational innovations, it has been found that they have a positive and significant influence on process IC (Camisón \& Villar-López, 2014), so this section will analyze IMS as an organizational innovation and its influence on process IC.

The adoption of more efficient MSs has been discussed to be the basis of improvements in productivity through important organizational overhauls that lead to the IC, which tendency has been found to be applied from the mid-80's in the US with the use of practices such as the TQM (Petroni et al., 2003). In this sense, the adoption of QMS has been classified as an organizational innovation in many researches (Petroni et al., 2003; Hoang et al., 2006; Moreno-Luzon et al., 2013) as well as related to the improvement of organizational performance (Prajogo \& Sohal, 2004).

Moreover, it has been studied that the adoption of QMSs such as ISO 9001 which has been widely applied worldwide but with varied success - have a significant positive effect on process innovation performance, specially due to the restructuring and application of the internal customer (Terziovski \& Guerrero, 2014). Nevertheless, QMSs and its practices are not always related to innovativeness, but process and strategic 
management are some of the key factors that positively impact the firm's innovation performance, where quality is considered a critical strategic factor for achieving a sustainable competitive advantage as long as it can shifted from quality to innovation (Hoang et al., 2006). The fact that even radical innovations can be achieved through the implementation of TQM when cultural change occurs within the company along with TQM implementation, implicates that companies shall not have a limited approach only based on quality assurance (Moreno-Luzon et al., 2013).

Furthermore, other studies have focused on studying the relationships between EMSs and its impact on process innovations. Ziegler \& Seijas Nogareda (2009) concluded that there are more complex relationships to be analyzed since the casualty of EMS on technological (process) innovations is ambiguous, which led to other researches where it has been found that programs such as the European Union's Eco-Management and Audit Scheme (EMAS) pressures firms to modify their processes in order to reduce resource waste which would necessarily promote process innovations (Lim \& Prakash, 2014); also, companies that have implemented ISO 14001 and that additionally have it as a mature MS are more likely to implement more environmental R\&D activities (Inoue et al., 2013), giving as a result the innovation of processes; nonetheless, other issues such as the culture (Wagner, 2009) interact for explaining those complex relationships.

Since a cultural change is necessary so that innovation occurs (Moreno-Luzon et al., 2013; Wagner, 2009), IMS becomes crucial by bringing with it a cultural change in the organization (Wilkinson \& Dale, 1999). Moreover, the casualty of the utilization of QMS and EMS over process innovations is evident in various researches, so integrating them into a single and more effective IMS would implicate better structured processes (Olaru et al., 2014), giving as a result that the more integrated the MS (i.e. integrating goals and procedures (Bernardo et al., 2009), the better process IC. Consequently, H1 is formulated:

H1: The level of IMS has a positive effect on process IC.

\subsection{IMS and Product IC}

When studying QMSs, some studies have found a negative relationship between TQM and product innovation, because it claims TQM is more focused on accomplishing certain product requirements related to quality rather than product newness, which leads to hindering product innovation (Atuahene-Gima, 1996). However, other studies have 
found that process and strategic management have a positive and significant effect on the development of new products (Hoang et al., 2006), so a better understanding is required about how process IC can be achieved by the implementation of QMSs, because in some cases it can happen when related to other factors that are still unclear.

From another perspective and at a macro level, empirical evidence suggests that the implementation of EMSs such as ISO 14001 has a positive effect on product innovations when they are measured through the number of patents implemented at the country level (Lim \& Prakash, 2014); more specifically at the firm level, it has been found that companies that have implemented ISO 14001 and held it during more years are more likely to show an incremental ratio (relative of total R\&D expenditures or sales) (Inoue et al., 2013), which serves as evidence that it causes the development of new products.

Referring to TQM, Prajogo \& Sohal (2006) indicate that product innovations cannot ignore quality aspects and that innovation should attempt to improve those aspects of quality, which is indeed a goal of the QMS; moreover, sustainable product innovations or green innovations occur when EMS goals have been accomplished (see e.g. Van Bommel, 2011; Cuerva et al., 2014). Notice that the process of IMS begins with the integration of goals (Bernardo, 2014), so as a consequence, if synergies (strategical, of resources and documentary) are achieved (Zeng et al., 2007), the more integrated MS are, the higher product IC it will achieve. This is congruent and complements with other results where organizational innovations have been proved to influence product IC (Camisón \& Villar-López, 2014), so H2 is developed as follows:

H2: The level of IMS has a positive effect on product IC.

\subsection{Process IC and Product IC}

Camisón \& Villar-López (2014) analyzed this relationship and concludes that process IC have a positive significant effect on product IC, and Organizational IC are also important for getting product IC through the improvement of process IC. From another perspective, technological capabilities (process IC) help to satisfy customer demand for product and service innovation (Veryzer, 1998), so process innovation influences positively product innovations (Fritsch \& Meschede, 2001). Consequently, a confirmation test is necessary to prove that, independently - but in the context - of the level of IMS and OI activities, product IC will be improved when having more process IC: 


\section{H3: Process IC have a positive influence on product IC}

\subsection{The role of Open Innovation (OI)}

It has been defined that open business models use a different approach of innovation, by considering the creation of value from the raw materials to the final customer - i.e. process innovations applied to this study - to new product or services, where the idea is to focus on both: the creation of value and the retention of a portion of that value (Chesbrough, 2006).

Even if the concept of OI has not been profoundly analyzed within the context of IMS, certain studies regarding the influence of QMSs on innovation have considered the importance of how open the firm is for getting different innovation outputs (Hoang et al., 2006); also, later studies have not found a direct effect of external collaborations on product innovations (Cuerva et al., 2014) but this does not reflect its moderating role. Moreover, product innovations are also related to the information received from the customers through the implementation of EMSs, (Wagner, 2008), which indicates that open innovation could affect the relationships formerly discussed.

It has been proposed but scarcely analysed that the combination of high internal cooperation and high external cooperation is the most successful combination between internal and external cooperation (Bouranta et al., 2009), therefore, since internal coordination is required for achieving higher levels of IMS - higher internal cooperation and because the IMS is required to be expanded to include the whole product chain and stakeholders - higher external cooperation - (Jørgensen et al., 2006), the level of IMS and the use of $\mathrm{Ol}$ activities are expected to interact in order to foster the $\mathrm{IC}$ discussed on $\mathrm{H} 1$ and H2. Fritsch \& Lukas (1999) discussed that cooperation between companies may also induce or stimulate innovation, but those relationships are much more complex and deserve to be analyzed beyond the simple monocasual explanations, so the idea of what has been previously defined as OI becomes more important in the context where the IMS is considered as an organizational innovation, since depending on how open the organization is and on how strong is the interaction with the internal organization and processes, innovation outputs differ. Therefore, OI activities moderate the interactions of the previously discussed $\mathrm{H} 1, \mathrm{H} 2$ and $\mathrm{H} 3$.

H4a: The existence of Ol activities moderates the effect of level of IMS on Process IC. 
H4b: The existence of Ol activities moderates the effect of level of IMS on Product IC.

H4c: The existence of Ol activities moderates the effect of the process IC on product IC.

The following figure is useful in order to understand the stated relationships included in the hypotheses:

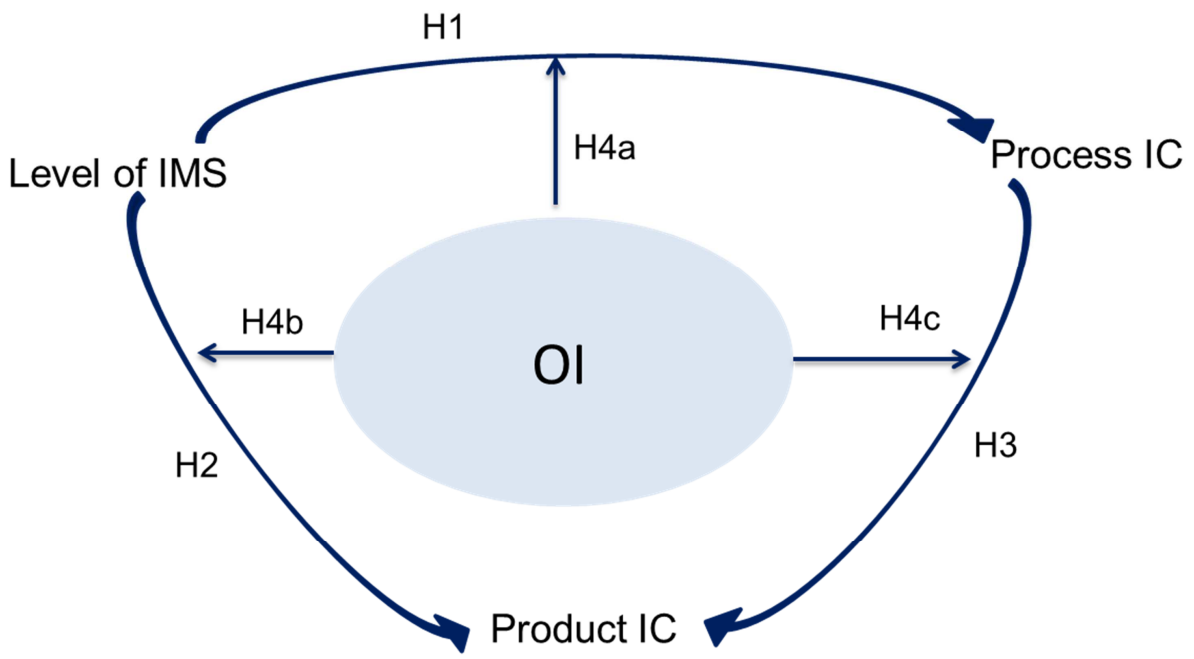

OI: Open Innovation activities

Figure 1. Proposed model

Source: Own elaboration

\section{Methodology}

\subsection{Population and sample selection}

This study is focused in Spanish companies because of its high concentration of ISO certificated companies worldwide, adopting the greatest density of both QMSs (ISO 9001) and EMSs with around 40 thousand and 15 thousand companies that have implemented ISO 9001 and ISO 14001 respectively (ISO, 2015), so the total population of this study is focused on a market where the implementation of meta-standards has been widely accepted and that is familiar with these practices, being this fact of relevance since the approach of this study is on studying the level of IMS.

In order to study all of the relationships proposed in this work, PITEC database was chosen since it contains information of surveys performed by the Spanish Foundation for 
Science and Technology (FECYT) and directly applied to Spanish companies for measuring the evolution of their technological activities since 2003 (FECYT, 2008).

The original database considers 118,859 observations obtained from 12,838 companies, of which only those observations that contained quality, environmental, process and product innovation, and open innovation indicators were selected, giving as a result a panel database of a total of 12,802 companies with information since 2004 until 2007 from a total of 56 industries (2 digit CNAE-93 code). It is important to consider that, since this study is based on a panel data, only those firms that had continuous information where considered due to the nature of the lagged models that are used for estimations (see section 3.3), giving as a result the selection of years 2004 to 2007; next, cleaning data was done by eliminating missing values of the selected variables through the Stata statistical software, where year 2007 was not considered due to collinearity. Consequently, the final sample is an unbalanced panel of at least 2 consecutive years (from 2004 to 2006) consisting of 23,193 observations from 9,765 companies. The definition and selection of such variables is discussed in the next subsection.

\subsection{Selection of variables}

\subsubsection{Dependent variables}

This study contains two dependent variables: process and product IC. Based on the RBV, capabilities are mandatory for the creation of a competitive advantage (i.e. innovations) (Song et al., 2007; Cruz-Cázares et al., 2013), so the indicators for measuring whether IC have or have not improved are based on whether firms have or have not implemented process and product innovations. Both variables are taken directly from the PITEC database as dummies $(0,1)$.

\subsubsection{Independent variables}

\section{Level of IMS}

The level of IMS is constructed from the data available in the PITEC database based on the fact that the dimensions for integrating are MS's resources, goals and processes (Karapetrovic \& Willborn, 1998, cited by Bernardo et al., 2009). However, the first aspect that must be integrated are goals (Karapetrovic, 2003), which relevance has also been pointed out in other empirical studies regarding the level of IMS (Jørgensen et 
al., 2006; Salomone, 2008; Bernardo et al., 2009). Thus, given that IMS increases organizational efficiency (Bernardo, 2014) it is expected that firms having fully IMS achieve the highest results of their MSs goals, as opposite to whether they have not even implemented or do not consider relevant at least one of them (non-integrated MS); also, companies having partially integrated MS: i) employ and consider relevant both MS and ii) do not have the highest score at least for one of the MS (see table 1).

Moreover, it is important to mention that MSs can be integrated into a single integrated MS whether it is certifiable or not (Bernardo et al., 2009) so QMS and EMS indicators for measuring each of them are, respectively, the "importance in the effect of the performance of quality and of the improvement of the environmental impact", which were both measured on a 4 point Likert-scale in the PITEC survey, and then deduced the level IMS by applying the following logic to each observation:

\begin{tabular}{|c|c|c|c|}
\hline Score of QMS and EMS indicators & $\begin{array}{l}\text { PITEC scores } \\
\text { combinations } \\
\text { (QMS - EMS) }\end{array}$ & Level of IMS & Codification \\
\hline Highest score for QMS and EMS & $1-1$ & $\begin{array}{l}\text { Fully } \\
\text { integrated }\end{array}$ & 3 \\
\hline $\begin{array}{l}\text { Both are relevant and employed, } \\
\text { but not having the highest score at } \\
\text { least for one of the MS }\end{array}$ & $\begin{array}{l}1-2 \\
1-3 \\
2-1 \\
2-2 \\
3-1 \\
3-2 \\
3-3\end{array}$ & $\begin{array}{l}\text { Partially } \\
\text { integrated }\end{array}$ & 2 \\
\hline $\begin{array}{l}\text { Not relevant or not employed at } \\
\text { least for one MS }\end{array}$ & $\begin{array}{l}1-4 \\
2-4 \\
3-4 \\
4-1 \\
4-2 \\
4-3 \\
4-4\end{array}$ & Non-integrated & 1 \\
\hline
\end{tabular}


Note: PITEC codification is 1 - High, 2 - Medium, 3 - Low, 4 - Not relevant / not employed

\section{Table 1. Definition of the Level of IMS}

Source: Own elaboration

\section{Open Innovation activities}

Measuring $\mathrm{OI}$ requires different indicators in order to get a better understanding on the factors that interact in its definition. First, it has been discussed on case studies the importance of building up long term collaborations for achieving common goals (Szeto \& Elson, 2000), so collaboration is the first indicator to be used for Ol, which is also a dichotomous variable.

Moreover, Laursen and Salter (2006) developed the concept of breadth and depth in order to investigate the range and profundity of open search strategies; thus, depth concept is of a special interest since the focus of this study is to research on the way OI moderates effects when external sources are used at a high degree. Depth "is defined in terms of the extent to which firms draw deeply from the different external sources or search channels" (Laursen \& Salter, 2006), and accordingly for measuring it, nine different agents that serve as external sources have been identified: suppliers, clients, competitors, consultants or R\&D private institutes, universities, public research centers, conferences, scientific journals and industry associations (Cruz-Cázares et al., 2012). Hence depth variable was determined by:

$$
\begin{aligned}
&(\text { External Source })_{i}=\left\{\begin{array}{l}
1 \text { if highly important to the firm } \\
0
\end{array}\right. \\
& \text { otherwise }
\end{aligned}
$$

Where, $i=\{1,2,3 \ldots .9\}=\{$ suppliers, clients, competitors, consultants or R\&D private institutes, universities, public research centers, conferences, scientific journals and industry associations\}.

Finally, and in order to get a better understanding given to the importance of R\&D activities, the fact a firm invests in external knowledge has also been considered important for studies regarding OI (see e.g. Cruz-Cázares et al., 2012). That is why the next variable to be measured as part of $\mathrm{Ol}$ is whether the firm has invested or not in external knowledge, which is consequently a dummy variable. 


\subsubsection{Control Variables}

Since this study aims to understand how relationships occur as a whole mechanism, the selected sample contains firms of different sizes and industries with data from 2004 to 2006, where all of the observations are continuous and contain no missing data among the panel as previously discussed on the sample selection. Consequently, these three factors are to be controlled.

Firms have been defined by the European Communities (2006) as Large, Medium and Small depending on the number of employees, under which, the characterization summarized in Table 2 was obtained:

\begin{tabular}{|lccc|}
\multicolumn{1}{|c}{ Size } & $\begin{array}{c}\text { No. of } \\
\text { employees }\end{array}$ & $\begin{array}{c}\text { Percentage } \\
(\%)\end{array}$ & Codification \\
\cline { 1 - 4 } Large & $\geq 250$ & 18.96 & 3 \\
\hline Medium & $<250$ & 30.51 & 2 \\
\hline Small & $<50$ & 50.54 & 1 \\
\hline
\end{tabular}

Table 2. Size of the firms

Source: Own elaboration

Additionally, the type of industries has been found to present different results on innovations (see e.g. Carruthers \& Vanclay, 2012; Hoang et al., 2006), and because this study considers all the 56 CNAE-93 industries, this is the next control variable to be measured. The last control variable is the year since this is a panel study.

Finally, all of the variables can be summarized in the following table:

\begin{tabular}{|c|c|c|c|c|c|c|}
\hline Type & Variable & $\begin{array}{l}\text { Simplified } \\
\text { Name }\end{array}$ & Mean & $\begin{array}{l}\text { Std. } \\
\text { Dev. }\end{array}$ & Min & $\operatorname{Max}$ \\
\hline \multirow{2}{*}{ Dependent } & $\begin{array}{l}\text { Product } \\
\text { innovation }\end{array}$ & IPROD & 0.67 & 0.47 & 0 & 1 \\
\hline & $\begin{array}{l}\text { Process } \\
\text { innovation }\end{array}$ & IPROC & 0.68 & 0.47 & 0 & 1 \\
\hline \multirow{4}{*}{ Independent } & $\begin{array}{l}\text { Level of } \\
\text { IMS }\end{array}$ & LIMS & 1.67 & 0.67 & 1 & 3 \\
\hline & $\begin{array}{l}\text { Investment } \\
\text { in external } \\
\text { knowledge }\end{array}$ & TEC & 0.07 & 0.26 & 0 & 1 \\
\hline & $\begin{array}{l}\text { External } \\
\text { Cooperation }\end{array}$ & EC & 0.37 & 0.48 & 0 & 1 \\
\hline & Depth & DTH & 1.10 & 1.40 & 0 & 9 \\
\hline
\end{tabular}




\begin{tabular}{|cllcccc|}
\hline \multirow{2}{*}{ Type } & Variable & $\begin{array}{c}\text { Simplified } \\
\text { Name }\end{array}$ & Mean & $\begin{array}{c}\text { Std. } \\
\text { Dev. }\end{array}$ & Min & Max \\
& Size & Size & 1.68 & 0.77 & 1 & 3 \\
\cline { 2 - 7 } Control & Industry & Ind & 26.25 & 16.54 & 0 & 55 \\
\cline { 2 - 7 } & Year & $\mathrm{Yr}$ & 2005.14 & 0.77 & 2004 & 2006 \\
\hline
\end{tabular}

Note: All of the variables are integers

Table 3. Summary of the selected variables

Source: Own elaboration

\subsection{Model development}

A logit model approach is selected in order to test the hypotheses, since process and product innovations are dichotomous dependent variables, so the resulting outputs are measured in accordance with the logistic function of each variable. With this approach, results allow to understand how odds of process and product innovations depend on the selected independent variables in terms of the direction (sign) as well as quantity (coefficients).

In order to identify the causal effects among the panel, it is taken into account the information of the available indicators during $t$ (for dependent variables) and $t-1$ (for independent variables) in order to determine how the casualty relationships occur among those years, given that successful innovations are determined by prior management actions rather than current (Atuahene-Gima, 1996). However, even if data of year 2007 was available, it was not considered in the analysis in order to avoid co-linearity in the logit analysis, so the final estimation was done with the information from 2004 to 2006, taking as reference year 2004.

For process innovations, it has been defined that its causes depend on the level of IMS and the moderating effect of Ol activities (i.e. its interactions with Ol activities), so the following model is resulting:

$$
\begin{aligned}
L(P R O C)=\beta_{0} & +\beta_{1} L I M S_{t-1}+\beta_{2}(L I M S * T E C)_{t-1}+\beta_{3}(L I M S * E C)_{t-1}+\beta_{4}(L I M S * D T H)_{t-1} \\
& +\beta_{5} \text { Size }+\beta_{6} \text { Ind }+\beta_{7} Y r
\end{aligned}
$$

Where, the expression $L(P R O C)$ describes the logistic function for process innovation, $\beta_{1}$ is important for contrasting the fact that the level of IMS has a positive effect on process IC (hypothesis $\mathrm{H} 1$ ), and the interactions between the level of IMS and OI 
activities (i.e. $\beta_{2}, \beta_{3}$ and $\beta_{4}$ ) are used for studying the moderating effect of those activities on process IC as described in hypothesis $\mathrm{H} 4 \mathrm{a}$.

Similarly, the following expression $L(P R O D)$ is defined as the logistic function for product innovations, which equation indicates the effects of process innovations, the level of IMS and the moderating effect OI activities (i.e., the interactions of process innovations and the level of IMS with those activities):

$$
\begin{aligned}
L(P R O D)=\beta_{0} & +\beta_{1} \text { LIMS }_{t-1}+\beta_{2} \text { PROC }_{t-1}+\beta_{3}(\text { LIMS } * \text { TEC })_{t-1}+\beta_{4}(\text { LIMS *EC })_{t-1} \\
& +\beta_{5}(\text { LIMS } * \text { DTH })_{t-1}+\beta_{6}(\text { PROC } * \text { TEC })_{t-1}+\beta_{7}(\text { PROC *EC })_{t-1} \\
& +\beta_{8}(\text { PROC } * D T H)_{t-1}+\beta_{9} \text { Size }+\beta_{10} \text { Ind }+\beta_{11} Y r
\end{aligned}
$$

$\beta_{1}$ is useful for contrasting the causality of the level of IMS on product IC (hypothesis $\mathrm{H} 2$ ), $\beta_{2}$ allows to understand the influence of process IC (hypothesis $\mathrm{H} 3$ ), and the interactions of $\mathrm{OI}$ activities with the level of IMS and process IC represented by $\beta_{3}, \beta_{4} \ldots \beta_{8}$ are crucial for contrasting its moderating effects on the level of IMS and on process IC, when studying product IC (hypotheses $\mathrm{H} 4 \mathrm{~b}$ and $\mathrm{H} 4 \mathrm{C}$ respectively).

Both equations are solved using the statistical software Stata with Maximum Likelihood estimation, and considering all of the control variables as categorical variables since each level could change the results.

\section{Results}

After proceeding with the methodology indicated above, results are shown in Table 4. It can be seen that models are accurate for explaining the dependent variables, since a Chi square $\left(\chi^{2}\right)$ for both process and product innovations regressions are significant at $1 \%$ $(p=0.000)$, which means that this is the probability of getting a $\chi^{2}$ as large as 822.2 and 890.2 for process and product innovations respectively. The standard deviation of the models is 3.713 and 4.193 (referred as sigma_u) for process and product innovations, which gives as a result a significant model at $1 \%{ }^{1}$.

Results indicate that the odds of process innovations are more likely to increase when having a higher level of IMS and also with its interactions with open innovation activities, since all of the effects are significant and have a positive sign (see Table 4), hence the odds result all of the positive and significant as well. Given these relations, it is

\footnotetext{
${ }^{1}$ Notice that $\operatorname{lnsig} 2 u=2 \log \left(\operatorname{sigma\_ } u^{2}\right)$
} 
important to highlight that the greatest odds of getting process innovations occur when the level of IMS is the highest (i.e. fully IMS) (odds =1.4492), and when they also use all the three OI activities, which moderate the effects of the level of IMS when: the company invests in external knowledge (odds $=1.4785$ ), they cooperate with external firms (odds = 1.136), and the most external sources used in a high extent for innovation the better (the greater the Depth value, the better - odds $=1.0354$ ).

Regarding product IC, results show that their odds increase when having fully IMS (odds $=1.6553$ ) as well as its combination with the investment on external knowledge (odds $=1.4092$ ), and also when the firm has implemented process innovations in combination with EC (odds $=1.6955$ ) and when using the most external sources at a high level (depth odds $=1.3711$ ). Nonetheless, firms that have only implemented process innovations but that have not been involved in any of the Ol activities (with focus on EC and number of external sources) are more likely to have lower product innovation capabilities (odds $=0.4971$ ). It can also be seen that the fact that firms invest in external knowledge (TEC) does not moderate the effect of process IC; also, the two OI activities that do not moderate the effect of the level of IMS are depth and the use of EC.

\begin{tabular}{|c|c|c|c|c|}
\hline & $\begin{array}{l}\quad(1) \\
\text { Process } \\
\text { Innovation }\end{array}$ & $\begin{array}{c}(2) \\
\text { Product } \\
\text { Innovation }\end{array}$ & $\begin{array}{l}\text { Process } \\
\text { Innovation } \\
\text { Odds }\end{array}$ & $\begin{array}{l}\text { Product } \\
\text { Innovation } \\
\text { Odds }\end{array}$ \\
\hline $\mathrm{IMS}_{\mathrm{t}-1}$ & $\begin{array}{c}0.371 * * \star \\
(0.0601)\end{array}$ & $\begin{array}{l}0.504 * * * \\
(0.0684)\end{array}$ & 1.4492 & 1.6553 \\
\hline$I M S x E C_{t-1}$ & $\begin{array}{c}0.224 * * * \\
(0.0411)\end{array}$ & $\begin{array}{c}0.136 \\
(0.0703)\end{array}$ & 1.2511 & NS \\
\hline $\mathrm{IMSxDTH}_{\mathrm{t}-1}$ & $\begin{array}{c}0.0348 * * \\
(0.0129)\end{array}$ & $\begin{array}{l}-0.0357 \\
(0.0214)\end{array}$ & 1.0354 & NS \\
\hline $\mathrm{IMSXTEC}_{\mathrm{t}-1}$ & $\begin{array}{l}0.391 * * * \\
(0.0709)\end{array}$ & $\begin{array}{l}0.343^{*} \\
(0.139)\end{array}$ & 1.4785 & 1.4092 \\
\hline $\mathrm{PROC}_{\mathrm{t}-1}$ & & $\begin{array}{c}-0.699 * * * \\
(0.105)\end{array}$ & & 0.4971 \\
\hline 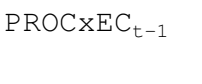 & & $\begin{array}{l}0.528 * * * \\
(0.149)\end{array}$ & & 1.6955 \\
\hline $\mathrm{PROC} \times \mathrm{TEC}_{\mathrm{t}-1}$ & & $\begin{array}{r}-0.260 \\
(0.280)\end{array}$ & & NS \\
\hline $\mathrm{PROCxDTH} \mathrm{H}_{\mathrm{t}-1}$ & & $\begin{array}{l}0.320 * * * \\
(0.0506)\end{array}$ & & 1.3771 \\
\hline -cons & $\begin{array}{r}0.297 \\
(0.366)\end{array}$ & $\begin{array}{l}-0.987 \star \\
(0.415)\end{array}$ & & \\
\hline
\end{tabular}




\begin{tabular}{|c|c|c|}
\hline Size & Yes & Yes \\
\hline Year & Yes & Yes \\
\hline Industry & Yes & Yes \\
\hline \multicolumn{3}{|l|}{$\operatorname{lnsig} 2 \mathrm{u}$} \\
\hline _cons & $\begin{array}{l}2.624 * \star \star \\
(0.0471)\end{array}$ & $\begin{array}{l}2.867 * \star \star \\
(0.0471)\end{array}$ \\
\hline N & 23193 & 23193 \\
\hline 11 & -11192.3 & -11039.7 \\
\hline \multicolumn{3}{|l|}{$\mathrm{Ng}$} \\
\hline $\operatorname{chi2}$ & 822.2 & 890.2 \\
\hline chi2_c & 4685.6 & 5346.6 \\
\hline sigma_u & 3.713 & 4.193 \\
\hline rho & 0.807 & 0.842 \\
\hline--------- & ------------ & ------------ \\
\hline $\begin{array}{l}\text { Standard } \\
\text { Yes indic } \\
\text { * } \mathrm{p}<0.05\end{array}$ & $\begin{array}{l}\text { n parenthese } \\
t \text { control va } \\
01, * \star * \quad p<0\end{array}$ & $\begin{array}{l}\text { IS: Not significant at } p=0.05 \\
\text { les were used }\end{array}$ \\
\hline
\end{tabular}

Table 4. Logit output

Source: Own elaboration - Stata outputs

The significant coefficients resulting of the logit models are illustrated in Figure 2.

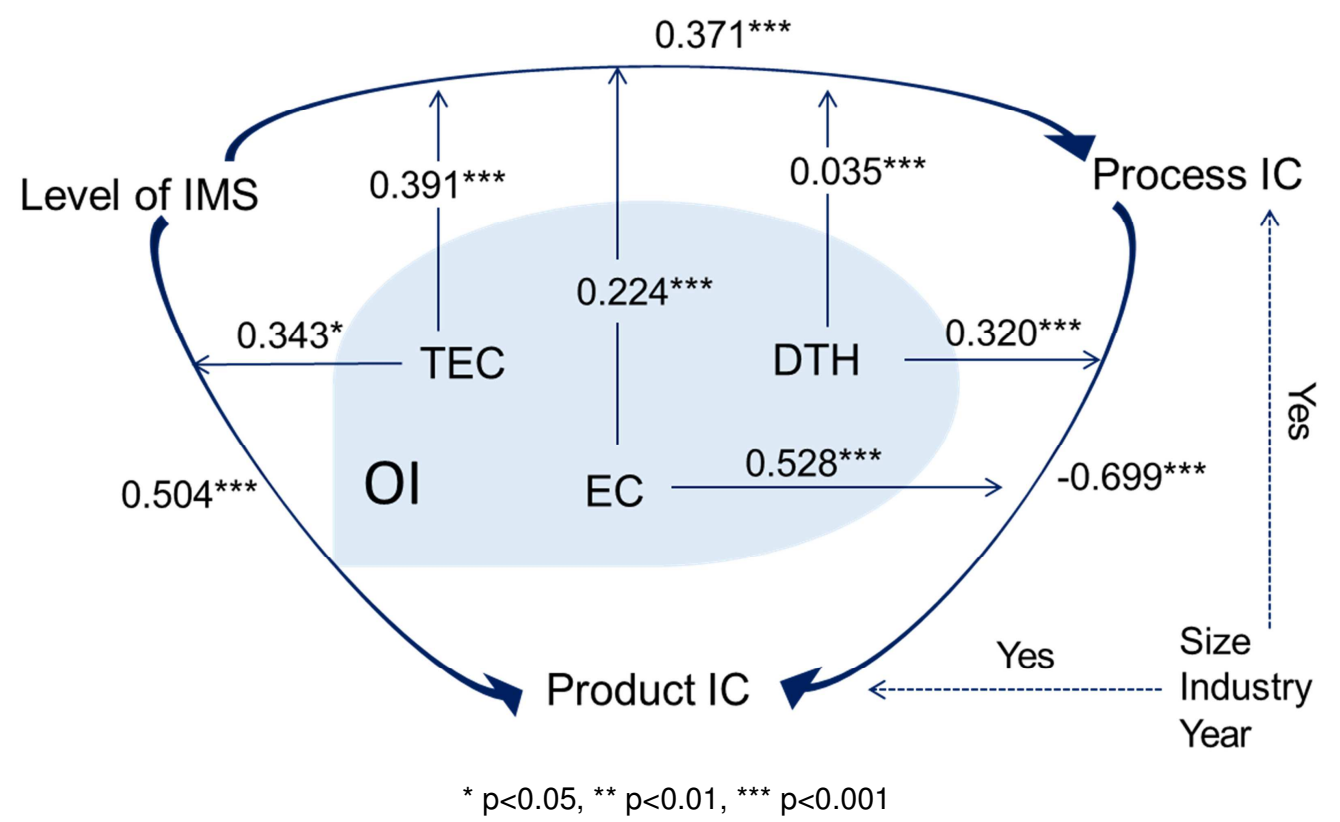

Ol: Open Innovation activities which include the following:

TEC - Investment in external knowledge / DTH - Depth /EC - External Cooperation Note: Yes indicates control variables are used.

Figure 2. Model significant coefficients

Source: Own elaboration

Finally control variables results show that bigger companies are more likely to improve their process and product IC; also, the last year of the analysis shows a significantly higher probability of improving process and product IC, which evidences the 
existence of the previous years' experience influence; finally, most industries are more likely to improve their product IC rather than process IC.

\section{Discussion and conclusions}

This study aims to analyze how the level of IMS influences on process and product $\mathrm{IC}$, where the role of $\mathrm{OI}$ is analyzed as a moderating effect on those relationships, for which two logit models were used for testing all the hypotheses.

When considering process innovation as the dependent variable, $\mathrm{H} 1$ is confirmed, since the level of IMS increases the odds of getting higher innovations, and thus it has a positive effect on process IC. This result shows that when a firm has integrated MSs at a higher level, its chances of innovating in processes the next year are also significantly higher, which indicates the evidence of a cause effect relationship between the level of IMS and process IC. This outcome is coherent with the previously discussed literature, in which it has been proposed that the level of IMS would lead to process innovations (Bernardo, 2014) and also shed lights on understanding how the interactions within MS and, consequently, its level of integration is an important factor in order to improve process IC. When analyzed separately, MS have generated debate on the ambiguity of whether EMS can be a cause for innovations (Ziegler \& Seijas Nogareda, 2009), or on how QMS are not enough if the company is only limited to quality (Moreno-Luzon et al., 2013), so this result is relevant in order to complement those previous concerns.

It is also confirmed $\mathrm{H} 2$ since it can be seen that higher levels of IMS increase the odds of having product innovations on the next year, which gives as a result the conclusion that the level of IMS has a positive effect on product IC. This study is one of the first in demonstrating empirically this result and is also coherent with previous literature relating the level of IMS with product innovations (Bernardo, 2014). In this sense, it is also important to point out that, even if other studies have not found significant the effect of organizational innovations on product IC (Camisón \& Villar-López, 2014), the level of IMS increases the chances of getting product IC, because in some cases, the sole fact of implementing MSs such as EMSs has been proved to have positive effects on product innovations (see e.g. Rehfeld et al., 2007) along with the fact that the improvement of IMS is achieved when goals are aligned between them (Karapetrovic, 2003). This could explain how product IC are positively increased when having higher levels of IMS. 
As a result, by accepting $\mathrm{H} 1$ and $\mathrm{H} 2$, this study contributes to literature by demonstrating empirically that, even if function specific MSs increase process IC and in some cases product IC, when adopting more than one MS and integrating them, having fully integrated MS leads to higher process and product IC than when having partially or even worse - non-integrated MS. This is one of the first studies in contributing with empirical results about these relationships.

In the next two paragraphs the main contributions of this paper are discussed. Regarding the moderating effect of $\mathrm{OI}$ activities and the level of IMS when analyzing its effects on process IC, all of those interactions are significant, which indicates that investing in external knowledge, cooperating with external firms and using intensively the most external sources moderate positively the effect of the level of IMS on process IC. This result validates $\mathrm{H} 4 \mathrm{a}$ and is coherent with other studies that have analyzed separately specific MSs, finding that QMSs are more effective for innovativeness depending on how open the organization is (Hoang et al., 2006), and that the adoption of new technologies is also related to EMS, where external knowledge is also important (Gavronski et al., 2012).

The interactions of OI activities and the level of IMS are also analyzed as a cause for product IC. Results show that the interaction of the level of IMS and investing in external knowledge is significant, but not with the use of external cooperation or the depth; therefore, $\mathrm{H} 4 \mathrm{~b}$ is partially accepted. Since studies for process innovations not necessarily apply for product innovations (Un \& Asakawa, 2015), it can be argued that this happens because cooperating with other companies, even if it is a higher extent, not necessarily implicates product innovations, but also the position of the firm in those networks is important for the new product development process (Mazzola et al., 2015).

The last result is obtained from the negative and significant effect of process IC on product IC, as opposite to what was specified in H3. Even if most of the investigations have found a positive relationship between both of them (see e.g. Camisón \& Villar-López, 2014), the existence of OI activities - specifically of external cooperation and depth changes the direction of this relationship and then increases the odds of getting product IC when process IC interact with $\mathrm{Ol}$ activities (since investing on external knowledge is not significant, $\mathrm{H} 4 \mathrm{c}$ is partially accepted), which is an important upshot from which it can be concluded that when analyzing how product innovations occur through the enhancement of process IC in the context of the implementation of IMS, the existence of Ol activities specially using EC at high extent - is necessary for this relationship to be positive. 
Moreover, using the concept of Ol activities sheds lights on the way a previously, but more ambiguous concept of market turbulence (Bernardo, 2014), moderates the effect of the level of IMS on innovation management performance.

This study has also implications for practitioners and researchers. The main managerial implication is related to the fact that the IMS is relevant in order to gain process and product IC on a more accurate way as if they would not do it. Additionally, results are not the same if enterprises do not perform OI activities, which give as a result the necessity for companies to implement and integrate MSs as well as using external sources in order to gain internal knowledge and then having a higher competitive advantage.

Research implications are mainly three. First, researchers must be aware of the importance of considering the IMS when analyzing MS, since this investigation sheds lights on the importance of analyzing the whole picture when enterprises have adopted more than one MS. Moreover, this consideration must also be done with Ol activities, since the results of product IC show that not considering the moderating effect of OI could lead even a negative result of process IC on product IC, which result is not intuitive if not considered the role of $\mathrm{Ol}$ activities. The second research implication is the need of constructing a more complete measurement quantitative model in order to determine how IMS could act as an exogenous or endogenous variable not only in its relationship with OI and process and product innovations, but also for studying its relationships with other constructs of interest such as financial performance, IMS benefits, Corporate Social Responsibility (CSR), among others. The third and last research implications is related to the fact that it has been detected there are different outputs on process and product IC when considering different industries (for process and product IC) and sizes (for process IC) of the companies, so further research must consider this differences in order to analyze concrete issues based on the showed results. Since this study is a first approach that has demonstrated empirically the importance of IMS and the role of $\mathrm{OI}$ as a moderating variable, researchers must analyze in-depth how this phenomenon occur, but focused on a specific industry and type of company.

Even if this study is based on theoretical and empirical evidence, it is not absent of limitations and therefore further investigation is required. Although the use of secondary databases is useful in order to have a first approach on new investigation lines, this is also a limitation since the information is not coded the same way it would have been defined on 
a specific survey; thus, product and process IC could be improved in future researches by using a continuous spectrum (e.g. Camisón \& Villar-López, 2014), and also the level of IMS had to be constructed supported on literature but could not be measured directly as previous literature suggests (e.g. Karapetrovic, 2003; Jørgensen et al., 2006; Bernardo et al., 2009). Nonetheless, all of the results suggest that, given the evidences of casualty, it is necessary to further investigate how the level of IMS produces the positive effects on process and product IC.

Due to the importance of Ol activities related to IMS, it is also important to deeper investigate this relationship, since it has been lately analyzed in other contexts how the chosen partners may affect to process and product innovations (Un \& Asakawa, 2015), so this idea must also be considered in further investigations related to IMS in order to have a deeper comprehension on the depth variable which was significant as a moderating effect in the causality of IMS over process innovations, as well as for the relationship between process and product IC. The same idea shall be considered for deeply understanding how External Cooperation acts as a moderating effect for the first equation.

It must also be pointed out that other empirical researches have considered that one of the benefits of the IMS is the better use of MS, which is a significant factor for improving process innovations (Simon \& Petnji Yaya, 2012), but the relationships with the benefits of IMS was far from the scope of this study, so further research could also consider this point of view by taking into account a more complete innovation management performance concept involving the integration benefits, financial results, processes and product innovations and other capabilities (Bernardo, 2014). This approach could lead to have a better comprehension on the causalities among IMS, by also considering OI activities due to its relevance highlighted in this study.

Finally, other quantitative models are suggested for constructing a more complete causal model, such as Structural Equation Modelling (SEM), for which it would be necessary to define an accurate measuring model for the level of IMS. This investigation settles the importance of deepening on empirical researches regarding IMS and innovation, with special attention to OI.

\section{References}

Antunes, G., Pires, A. \& Machado, V., 2009. Process improvement measures in social 
area organisations: A study in institutions for elderly: survey results. The TQM Journal, 21(4), pp.334-352.

Atuahene-Gima, K., 1996. Market orientation and innovation. Journal of Business Research, 35(2), pp.93-103.

Beckmerhagen, I. a., Berg, H.P., Karapetrovic, S.V. \& Willborn, W.O., 2003. Integration of management systems: focus on safety in the nuclear industry. International Journal of Quality \& Reliability Management, 20(2), pp.210-228.

Bernardo, M., 2014. Integration of management systems as an innovation: a proposal for a new model. Journal of Cleaner Production, 82, pp.132-142.

Bernardo, M., Casadesus, M., Karapetrovic, S. \& Heras, I., 2009. How integrated are environmental, quality and other standardized management systems? An empirical study. Journal of Cleaner Production, 17(8), pp.742-750.

Van Bommel, H.W.M., 2011. A conceptual framework for analyzing sustainability strategies in industrial supply networks from an innovation perspective. Journal of Cleaner Production, 19(8), pp.895-904.

Bouranta, N., Chitiris, L. \& Paravantis, J., 2009. The relationship between internal and external service quality. International Journal of Contemporary Hospitality Management, 21(3), pp.275-293.

Camisón, C. \& Villar-López, A., 2014. Organizational innovation as an enabler of technological innovation capabilities and firm performance. Journal of Business Research, 67(1), pp.2891-2902.

Carruthers, G. \& Vanclay, F., 2012. The intrinsic features of Environmental Management Systems that facilitate adoption and encourage innovation in primary industries. Journal of Environmental Management, 110, pp.125-134.

Chesbrough, H.W., 2006. Open Business Models: How to Thrive in the New Innovation Landscape. Researchtechnology Management, 50, p.256.

Comunidades Europeas, 2006. La nueva definición de PYME, Available at: http://europa.eu.int/comm/enterprise/enterprise_policy/sme_definition/index_es.htm.

Cruz-Cázares, C., Bayona-Sáez, C. \& García-Marco, T., 2013. You can’t manage right what you can't measure well: Technological innovation efficiency. Research Policy, 42(6-7), pp.1239-1250.

Cruz-Cázares, C., Smits, A., Berends, H., Reymen, I., Anzola, P., Bayona-Sáez, C., García-Marco, T., Schubert, M. \& Sturm, F., 2012. BMOI Report - A Regional Comparison of Open Innovation Practices,

Cuerva, M.C., Triguero-Cano, Á. \& Córcoles, D., 2014. Drivers of green and non-green innovation: Empirical evidence in Low-Tech SMEs. Journal of Cleaner Production, 68, pp.104-113.

FECYT, 2008. Panel de Informacion Tecnológica - PITEC. Available at: http://icono.fecyt.es/PITEC/Paginas/por_que.aspx.

Fritsch, M. \& Lukas, R., 1999. Innovation, Cooperation and the Region. In D. Audretsch \& R. Thurik, eds. Innovation, Industry Evolution and Employment. Cambridge: Cambridge University Press, pp. 157-181.

Fritsch, M. \& Meschede, M., 2001. Product Innovation, Process Innovation, and Size. Review of Industrial Organization, 19(3), pp.335-350. 
Gavronski, I., Klassen, R.D., Vachon, S. \& Nascimento, L.F.M. Do, 2012. A learning and knowledge approach to sustainable operations. International Journal of Production Economics, 140(1), pp.183-192.

Hoang, D.T., Igel, B. \& Laosirihongthong, T., 2006. The impact of total quality management on innovation: Findings from a developing country. International Journal of Quality \& Reliability Management, 23(9), pp.1092-1117.

Inoue, E., Arimura, T.H. \& Nakano, M., 2013. A new insight into environmental innovation: Does the maturity of environmental management systems matter? Ecological Economics, 94, pp.156-163.

ISO, 2013. Integrated management systems. Available at: http://www.iso.org/iso/home/news_index/news_archive/news.htm?Refid=Ref1709.

ISO, 2015. ISO Survey. Available at: http://www.iso.org/iso/iso-survey.

Jørgensen, T.H., Remmen, A. \& Mellado, M.D., 2006. Integrated management systems Three different levels of integration. Journal of Cleaner Production, 14, pp.713-722.

Karapetrovic, S., 2003. Musings on integrated management systems. Measuring Business Excellence, 7(1), pp.4-13.

Karapetrovic, S. \& Willborn, W., 1998. Integrated audit of management systems. International Journal of Quality \& Reliability Management, 15(7), pp.694-711.

Laursen, K. \& Salter, A., 2006. Open for innovation: The role of openness in explaining innovation performance among U.K. manufacturing firms. Strategic Management Journal, 27(2), pp.131-150.

Lim, S. \& Prakash, A., 2014. Voluntary regulations and innovation: The Case of ISO 14001. Public Administration Review, 74(2), pp.233-244.

Llach, J., de Castro, R., Bikfalvi, A. \& Marimon, F., 2007. The Relationship between Environmental Management Systems and Organizational Innovations. Human Factors and Ergonomics in Manufacturing, 17(5), pp.475-484.

Mazzola, E., Perrone, G. \& Kamuriwo, D.S., 2015. Network embeddedness and new product development in the biopharmaceutical industry: The moderating role of open innovation flow. International Journal of Production Economics, 160, pp.106-119.

Moreno-Luzon, M.D., Gil-Marques, M. \& Valls-Pasola, J., 2013. TQM, innovation and the role of cultural change. Industrial Management \& Data Systems, 113(8), pp.11491168.

OECD, 2005. The measurement of scientific and technological activities Oslo Manual. Proposed Guidelines for Collecting and Interpreting Technological Innovation Data. European Commission and Eurostat.

Olaru, M., Maier, D., Nicoară, D. \& Maier, A., 2014. Establishing the basis for Development of an Organization by Adopting the Integrated Management Systems: Comparative Study of Various Models and Concepts of Integration. Procedia - Social and Behavioral Sciences, 109, pp.693-697.

Petroni, G., Dormio, A.I., Nosella, A. \& Verbano, C., 2003. The TQM trajectories in research and development: two Italian cases. European Journal of Innovation Management, 6(4), pp.239-252.

Prajogo, D., Tang, A.K.Y. \& Lai, K.-H., 2014. The diffusion of environmental management system and its effect on environmental management practices. International Journal of Operations \& Production Management, 34(5), pp.565-585. 
Prajogo, D.I. \& Sohal, A.S., 2006. The integration of TQM and technology/R\&D management in determining quality and innovation performance. Omega, 34(3), pp.296-312.

Prajogo, D.I. \& Sohal, A.S., 2004. The multidimensionality of TQM practices in determining quality and innovation performance - An empirical examination. Technovation, 24(6), pp.443-453.

Radonjic, G. \& Tominc, P., 2011. The impact and significance of ISO 14001 certifications on the adoption of new technologies. Management of Environmental Quality: An International Journal, 17(6), pp.707-727.

Rehfeld, K.M., Rennings, K. \& Ziegler, A., 2007. Integrated product policy and environmental product innovations: An empirical analysis. Ecological Economics, 61(1), pp.91-100.

Salomone, R., 2008. Integrated management systems: experiences in Italian organizations. Journal of Cleaner Production, 16, pp.1786-1806.

Simon, A. \& Petnji Yaya, L.H., 2012. Improving innovation and customer satisfaction through systems integration. Industrial Management \& Data Systems, 112(7), pp.1026-1043.

Song, M., Di Benedetto, C.A. \& Nason, R.W., 2007. Capabilities and financial performance: the moderating effect of strategic type. Journal of the Academy of Marketing Science, 35(1), pp.18-34.

Szeto \& Elson, 2000. Innovation capacity: working towards a mechanism for improving innovation within an inter-organizational network. The TQM Magazine, 12(2), pp.149158.

Terziovski, M. \& Guerrero, J.-L., 2014. ISO 9000 quality system certification and its impact on product and process innovation performance. International Journal of Production Economics, 158, pp.197-207.

Un, C.A. \& Asakawa, K., 2015. Types of R\&D Collaborations and Process Innovation: The Benefit of Collaborating Upstream in the Knowledge Chain. Journal of Product Innovation Management, 32(1), pp.138-153.

Veryzer, R.W., 1998. Discontinuous Innovation and the New Product Development Process. Journal of Product Innovation Management, 15(4), pp.304-321.

Wagner, M., 2008. Empirical influence of environmental management on innovation: Evidence from Europe. Ecological Economics, 66(2-3), pp.392-402.

Wagner, M., 2009. National culture, regulation and country interaction effects on the association of environmental management systems with environmentally beneficial innovation. Business Strategy and the Environment, 18(2), pp.122-136.

Wagner, M., 2007. On the relationship between environmental management, environmental innovation and patenting: Evidence from German manufacturing firms. Research Policy, 36(10), pp.1587-1602.

Wilkinson, G. \& Dale, B.G., 1999. Integrated management systems: an examination of the concept and theory. The TQM Magazine, 11(2), pp.95-104.

Zeng, S.X., Shi, J.J. \& Lou, G.X., 2007. A synergetic model for implementing an integrated management system: an empirical study in China. Journal of Cleaner Production, 15, pp.1760-1767.

Ziegler, A. \& Seijas Nogareda, J., 2009. Environmental management systems and 
technological environmental innovations: Exploring the causal relationship. Research Policy, 38(5), pp.885-893. 